\section{ECCOMAS}

\section{Proceedia}

COMPDYN 2021

$8^{\text {th }}$ ECCOMAS Thematic Conference on Computational Methods in Structural Dynamics and Earthquake Engineering M. Papadrakakis, M. Fragiadakis (eds.) Streamed from Athens, Greece, 28 - 30 June 2021

\title{
DYNAMIC AND VIBROACOUSTIC RESPONSE OF TIMBER FLOOR PANELS. MEASUREMENTS AND NON-LINEAR NUMERICAL SIMULATIONS
}

\author{
Magdalini Titirla ${ }^{1}$, Sarah Benakli ${ }^{1}$, and Walid Larbi ${ }^{1}$ \\ ${ }^{1}$ Structural Mechanics and Coupled Systems Laboratory (LMSSC), Conservatoire National des Arts et \\ Métiers (CNAM), Paris, \\ 292 rue Saint-Martin, 75141 Paris Cedex 03, France \\ \{magdalini.titirla, sarah.benakli, walid.larbi\}@lecnam.net
}

\begin{abstract}
The present work concerns the dynamic and vibroacoustic response of timber floor panels as well as the study of the effect of material nonlinearities and damping. Each panel is composed of glued laminated beams and wood constituting the floor. The dimensions of the panels are defined to ensure appropriate implementation and transport conditions. For these reasons, the width of the panels is fixed at $2.40 \mathrm{~m}$, and the length is $7.2 \mathrm{~m}$. Two types of floor panels were investigated with and without struts. A numerical approach based on $3 D$ finite element method is used to solve the problem. Our finite element model and the mechanical properties of the used materials are first validated from comparisons with experimental tests carried out in statics [1]. A dynamic non-linear analysis of the timber floor panels has been then conducted under a walking time history and the vibroacoustic response of the system is finally investigated.
\end{abstract}

Keywords: Timber structures, dynamic analysis, vibroacoustic, numerical and experimental measurements, non-linear.

ISSN:2623-3347 C 2021 The Authors. Published by Eccomas Proceedia.

Peer-review under responsibility of the organizing committee of COMPDYN 2021.

doi: $10.7712 / 120121.8678 .19159$ 


\section{INTRODUCTION}

The use of wood as construction material increased in Europe during the last decades. Compared to steel or reinforced concrete buildings, the timber buildings are more sensitive to dynamic loading, especially in terms of vibroacoustic comfort. Furthermore, due to the complexity of wood material and different structural details it is more difficult to predict the accurate response due to dynamic loading.

Floor vibrations and structure-borne sound in residential buildings can be induced by several sources such as people walking indoors, machines vibration. Excessively high sound and/or vibration levels cause annoyance and discomfort for residents. Low frequency prediction tools are needed to access the dynamic behavior of a timber floor in an early design phase to ultimately reduce the low frequency impact noise. This highlights the need to improve the design of multi-story timber buildings such that vibration levels and the need of further investigation on this field.

In the European countries, the vibration of timber floors is regulated by the serviceability limit states (SLS) requirements of Eurocode [2]. In addition, a lot of researchers have started to investigate this field. Initially, the vibration issues of different types of flooring systems (composite, concrete, steel with timber) was identified under the action of human activities by Bachmann \& Ammann [3], Williams \& Waldron [4], Da Silva et al. [5] and Ebrahimpour \& Sack [6].

In the present work attention is focused on the dynamic and vibroacoustic response of timber floor panels as well as the study of the effect of material nonlinearities and the damping ration. The first part of this study focuses on the validation of the finite elements (FE) model with the appropriate selected experimental results, in order to be a reliable tool for the further part of this study. After the validation, dynamic analyses were conducted under a walking load time history of a person in the middle of each floor panel, and then the vibroacoustic of these panels are presented.

\section{A SHORT DESCRIPTION OF THE INVESTIGATED TIMBER FLOOR PANELS}

Two types of floor panels were investigated (with and without struts). The floor panels have been proposed by Fuentes et al [1] and analyzed only in static analysis. The dimensions of the panels were defined to ensure appropriate implementation and transport conditions. For these reasons, the width of the panels was fixed at $2.40 \mathrm{~m}$, and the length was $7.2 \mathrm{~m}$. Each floor panel was consisted of glued laminated beams, joins and floor of $25 \mathrm{~mm}$. The first one, referred to herein as PAN_Fl, consisted of two (2) beams, thirteen (13) joists and the floor, while the second one, referred to herein as PAN_Fl_struts, was like the previous one but with struts (Figure 1). The design of these floor panels meted the requirement of Part 1-1 of Eurocode 5 [2]. The material of the main parts of the floor panels was categorized in the class GL32h.

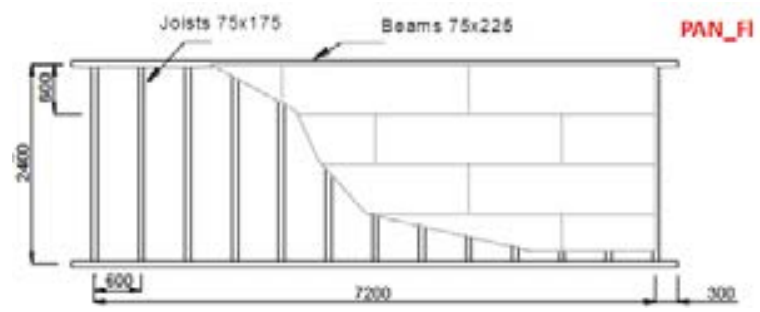

(a)

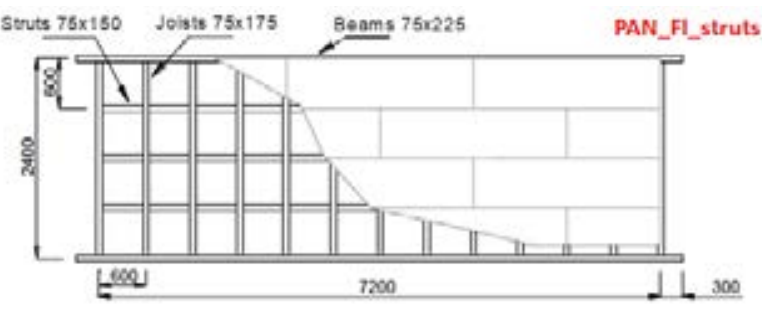

(b)

Figure 1: Geometric configuration of: (a) PAN_Fl, (b) PAN_Fl_struts (values in mm). 


\section{VALIDATION OF FEM FOR FLOOR PANELS IN STATIC ANALYSIS}

The FE method is a widely employed approach to develop numerical prediction models in construction industry and more and more researchers are used it [7-9]. By performing numerical simulations, experimental acoustical tests can be reduced, and parametric studies can also be carried out to investigate the influence of specific geometrical changes in construction as well as the influence of the variations/uncertainties in material properties, which always have a mark able influence on the results [10-12].

The FE analysis calibration study included analytical modelling of the two panels. Elastoplastic orthotropic material models were used with non-linear hardening associated with material densification. Table 1 summarises the details of the material properties.

Table 1: Main material parameters.

\begin{tabular}{ccccccccc}
\hline Quality & $\begin{array}{c}\mathrm{E}_{1} \\
(\mathrm{MPa})\end{array}$ & $\begin{array}{c}\mathrm{E}_{2} \\
(\mathrm{MPa})\end{array}$ & $\begin{array}{c}\mathrm{E}_{3} \\
(\mathrm{MPa})\end{array}$ & $\begin{array}{c}\mathrm{f}_{\mathrm{m}, \mathrm{k}} \\
(\mathrm{MPa})\end{array}$ & $\mathrm{v}_{12}$ & $\mathrm{v}_{13}$ & $\mathrm{v}_{23}$ & $\begin{array}{c}\rho \\
\left(\mathrm{kg} / \mathrm{m}^{3}\right)\end{array}$ \\
\hline GL32h & 13500 & 450 & 450 & 32.5 & 0.35 & 0.35 & 0.09 & 420 \\
\hline
\end{tabular}

The 3D FEM model geometry reproduced the actual geometry of the experiments, as well as the simulation used the same boundary conditions and loading as in the experimental program (see Figure 1 and 2).

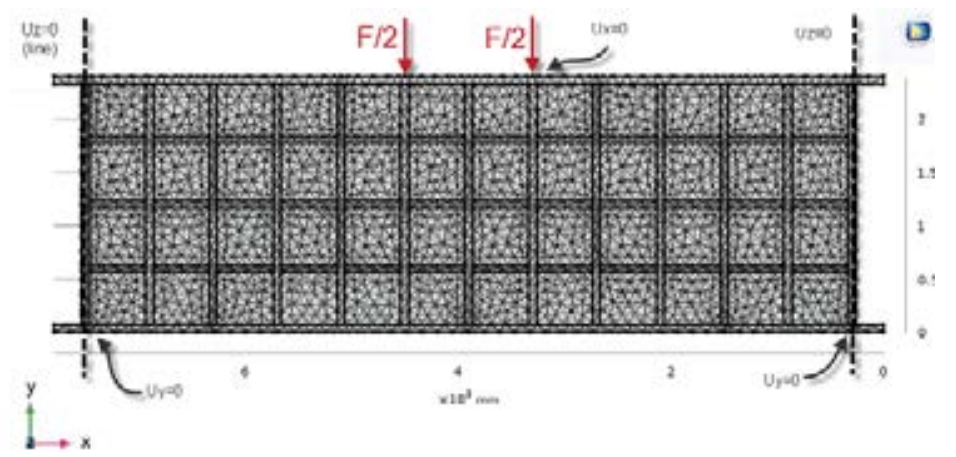

Figure 2: Configuration of floor panels PAN_Fl_struts.

Alternative finite element models were conducted to identify the best meshing. It is known that a finer mesh density provides higher accuracy but also increases the computational time without improving substantially the accuracy of the results, therefore, a tradeoff between time and accuracy becomes crucial. In our model tetrahedral solid elements were used with high level of optimization in order to avoid inverted curved elements, too large or too small elements. In total 16335 elements were used for the PAN_Fl and 21954 for the PAN_Fl_struts.

In this section, static analyses have been performed with increasing load until the failure of the panels. The nonlinear solver uses an affine invariant form of the damped Newton method. The numerical results were compared with the experimental ones and the validation of the model was based on: (i) the force-displacement curves, and (ii) the deformation shape of the bottom beam during different loads, for the both floor panels.

Figures 3 and 4 compare the experimental and the numerical results of the panels PAN_Fl and PAN_Fl_struts respectively. Part (a) presents the force - displacement curves at the middle of the panel, part (b) illustrates the shape of the deflection along the bottom beam of each panel, while part (c) shows the deformation shape of each panel for a selected force $(45 \mathrm{kN}$ for the panel PAN_Fl and $65 \mathrm{kN}$ for the panel PAN_Fl_struts). It is important to notice that in the Figures $3 \mathrm{c}$ and $4 \mathrm{c}$ the panels are illustrated without the floors in order to verify the shape of the beams and the joists. As it is shown, the numerical monotonic curve follows the envelope 
of the experimental response. Therefore, the numerical loading curve can be reliably used to assess the stiffness and strength of the investigated panels and the proposed FE model in order to establish the individual and combined effects of various parameters on the response of the panels and, in so doing, to identify the significance of the numerical contribution to produce results that are harder to obtain experimentally.

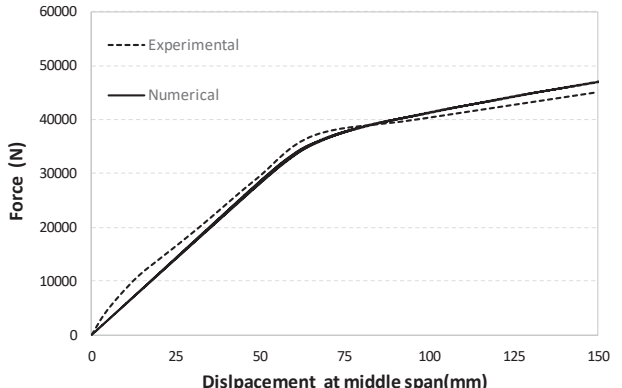

(a)

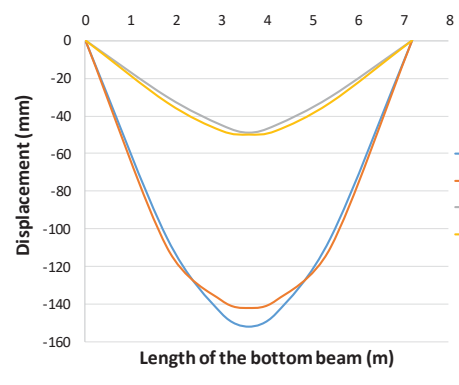

(b)

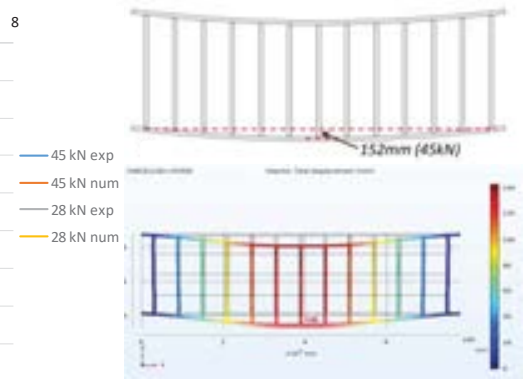

(c)

Figure 3: Comparison of experimental and numerical results for the panel PAN_Fl.

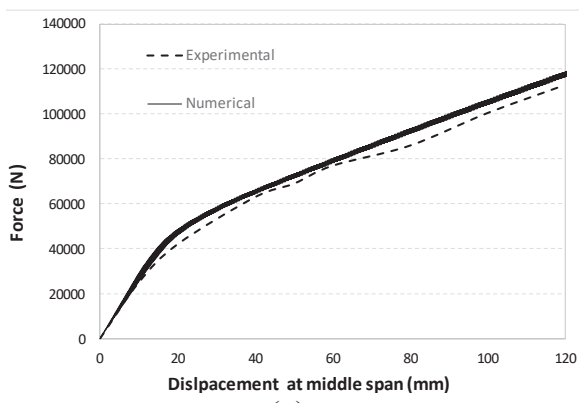

(a)

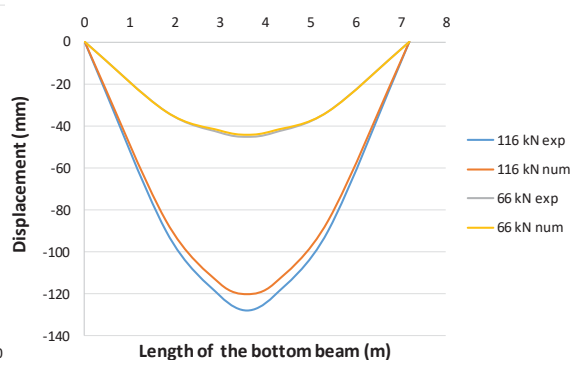

(b)

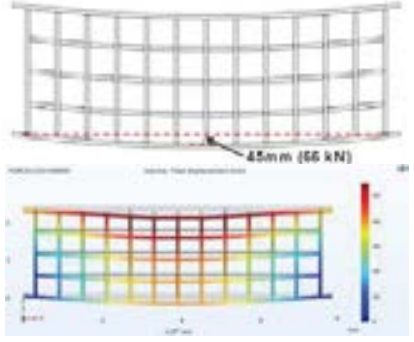

(c)

Figure 4: Comparison of experimental and numerical results for the panel PAN_Fl_struts.

\section{DYNAMIC ANALYSIS}

The aim of this section is to use the proposed FE model in order to investigate the dynamic response of these panels in different vibration loading. A dynamic analysis of a structure differs from a corresponding static analysis mainly in two ways. While a static analysis assumes that a structure is in complete equilibrium with its surroundings a dynamic analysis takes into consideration the structure's true response when subjected to a force. Furthermore, a static analysis treats the loads as static, which means that they varies sufficiently slowly with time. On the other hand, there are a lot of loads that in fact are dynamic, that is, they varies rather quickly with time [13]. Vibrations may be described as oscillations around the statically equilibrium of a structure [14]. Vibrations arise when time-varying disturbances, either forces or displacements, interact with the inertia properties of an affected medium. The dynamic response of a structural system is affected by the material properties, the damping, the properties of the system as whole, and the presence of non-structural elements, such as floor coverings, ceilings etc [15].

Damping is the most important parameter which significantly influences the response of occupants to floor vibrations even though it hardly affects the fundamental frequency $f_{i}$. This is because damping is an intrinsic property of structural systems that influences oscillation amplitudes and the rate of decay under forced and free vibrations, respectively [16]. Previous research has shown that the timber floors constructed with engineered I-joists had a damping ratio $\zeta=2-4 \%$ [17] while the floors with metal-webbed joists only had a very low damping 
ratio $\zeta=0.86 \%$ which is below $1 \%$ [18]. This indicates that the design damping ratio $\zeta=1 \%$ proposed in EN 1995-1-1 [2] may not cover all timber floor types so an average damping ratio $\zeta=2 \%$ is proposed in order to cover most practical cases [19].

\subsection{Case study}

In this study the two panels of PAN_Fl and PAN_Fl_stucts were analysed under a walking loading time history of one person $75 \mathrm{~kg}$ in the middle of each panel (on the spot) with a total duration of $2.6 \mathrm{sec}$. In this study only the effects of a damping ration were presented. Figure 5 describes the investigated panels with the details of boundary conditions, load time histories, while Table 2 summarizes the investigated cases. The beams of the panels are the part that is being connected with the columns of the structures. The stiffness of these connections can varies as it depends on the type of the connection as Titirla et al have been presented [20-23], but in this study only the case of a rigid connection was presented.

Each harmonic of the loading function can cause resonance with a natural frequency of the floor, and it is the walking pace frequency that gives the worst-case response that should be used for design. The pace frequency $\left(f_{p}\right)$ for walking has a mean value of $2.0 \mathrm{~Hz}$. The standard walking load of a person can then be described as a series of consecutive steps, where each step is given by a polynomial function which is proposed by Harpel et al. [24].

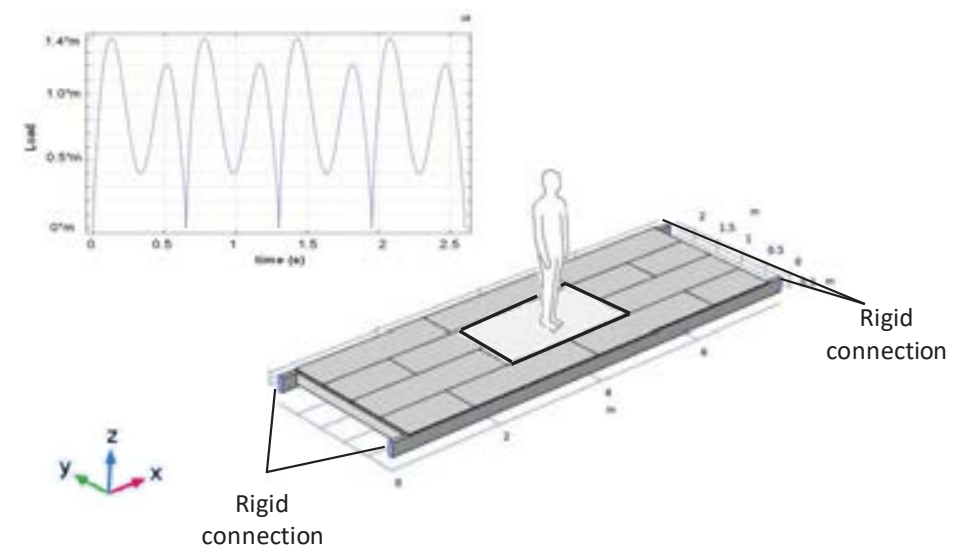

Figure5: Walking time history and boundary condition of the panels.

Table 2: Description of the case studies.

\begin{tabular}{cccc}
\hline Panel & $\begin{array}{c}\text { Boundary con- } \\
\text { ditions }\end{array}$ & Damping & Name \\
\hline PAN_Fl & Rigid & $0 \%$ & PAN_Fl \\
PAN_Fl & Rigid & $1 \%$ & PAN_Fl_d \\
PAN_Fl_struts & Rigid & $0 \%$ & PAN_Fl_struts \\
PAN_Fl_struts & Rigid & $1 \%$ & PAN_Fl_struts_d \\
\hline
\end{tabular}

\subsection{Comparison of the results}

In the present numerical study a damping ratio equal to $1 \%$ was selected, according to EN 1995-1-1 [2]. The comparison of the results, given in Figure 5, shows that the maximum vertical displacement was reduced $1.4 \%$ for the PAN_Fl and $0.5 \%$ for the PAN_Fl_struts according to damping, while the maximum acceleration in the middle of the span was reduced equal to $10 \%$ and $2.5 \%$ respectively. It can be observed that each transient vibration signal contains a high initial peak and decays. The peak values of a transient vibration are governed by system stiffness and mass, but not by damping. Damping is a measure of how quickly the 
response of vibrating system decay after the loading period; as a result the effects of the damping during the walking loading of $2.6 \mathrm{sec}$ were not as much remarkable.

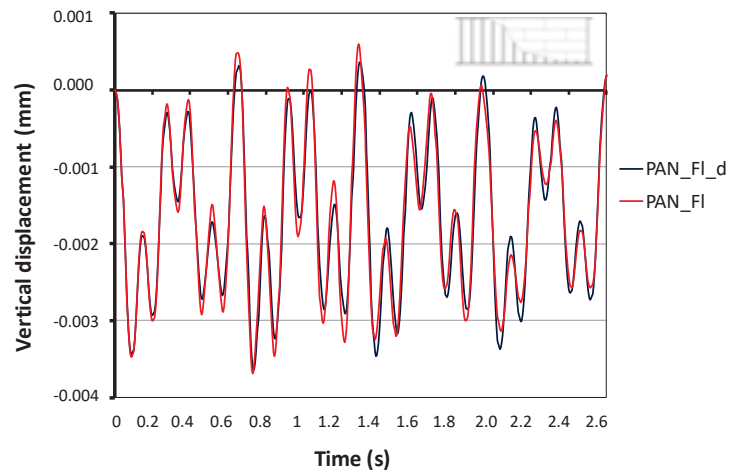

(a)

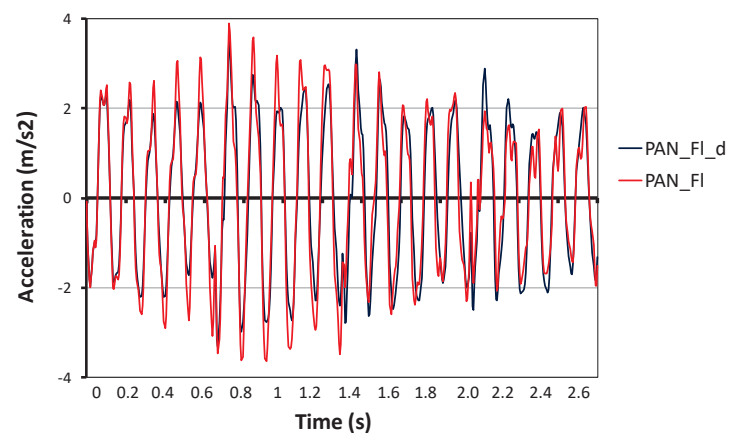

(c)

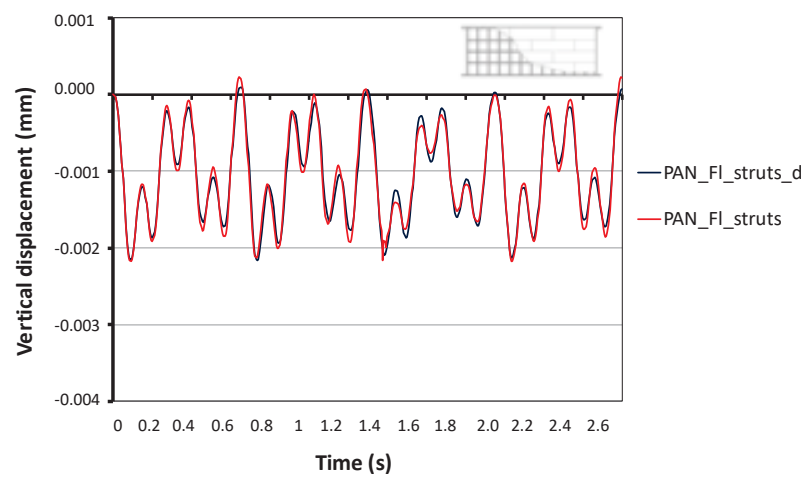

(b)

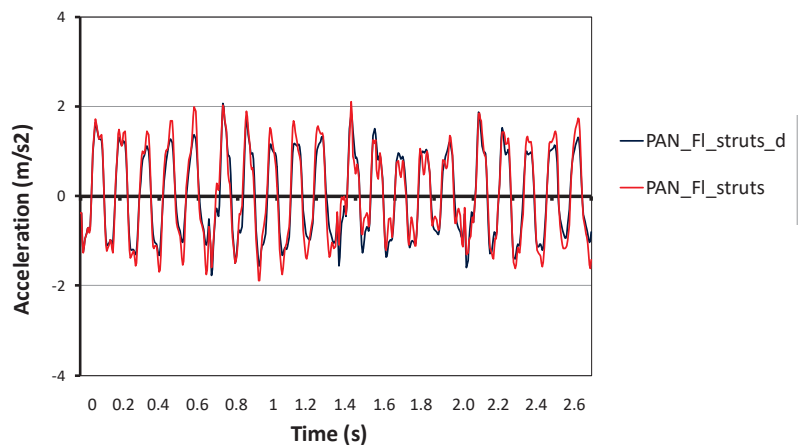

(d)

Figure 5: Time histories of (a) the vertical displ. at the middle of the panel PAN_Fl, (b) the vertical displ. at the middle of the panel PAN_Fl_struts, (c) the acceleration at the middle of the panel PAN_Fl, (d) the acceleration at the middle of the panel PAN_Fl_struts.

\section{VIBROACOUSTIC}

Structures when subjected to time varying loads will vibrate and generate acoustic waves. The characteristics of the acoustic waves generated by the structure may depend on the vibration behavior of the structure, which in turn depends on different factors such as the properties of structural materials, types of loads, location of load application, structural configuration, boundary conditions, etc. The determination of the true vibro-acoustic characteristics of a structure is essential for the correct prediction of the actual vibration and sound radiation behaviors of the structure. Therefore, because of its importance, the vibro-acoustic characterization of structures has drawn close attention and a lot of researchers are working in this field [25-27].

The aim of this session is to study the influence of the two configurations (PAN_Fl and PAN_Fl_struts) on the impact sound transmission of a floor. For this reason the previous panels with the rigid connections were investigated; but this time the analyses were focused on the frequency domain. The Acoustics interface uses the Pressure Acoustics, Frequency Domain module to solve the governing wave equation that is complemented with sound sources as boundary condition. The speed of the sound in the air equal to $343 \mathrm{~m} / \mathrm{s}$ and the density of $1.2 \mathrm{~kg} / \mathrm{m} 3$ were taken into account in this study. 
The radiated sound power level for the reference case is shown in Figure 7. The large amplitude peaks observed in the frequency response make it possible to identify the critical resonance frequencies to be avoided.

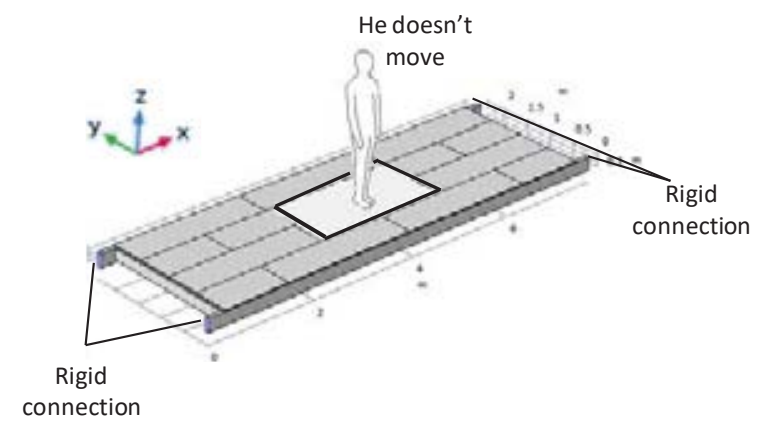

(a)

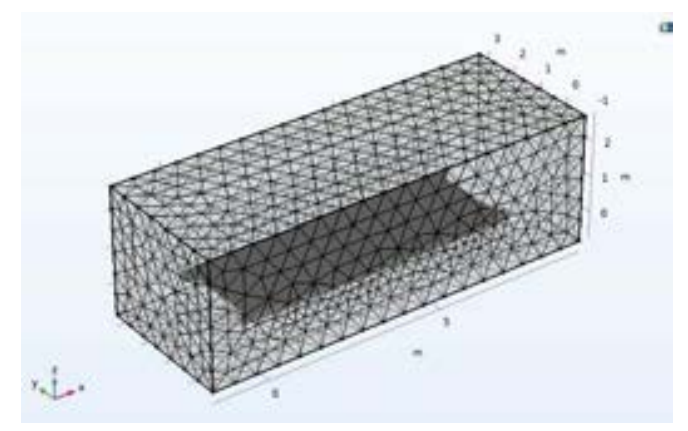

(b)

Figure6: (a) the model with the additional mass and the boundary conditions, (b) the mesh for the floor elements and the air.

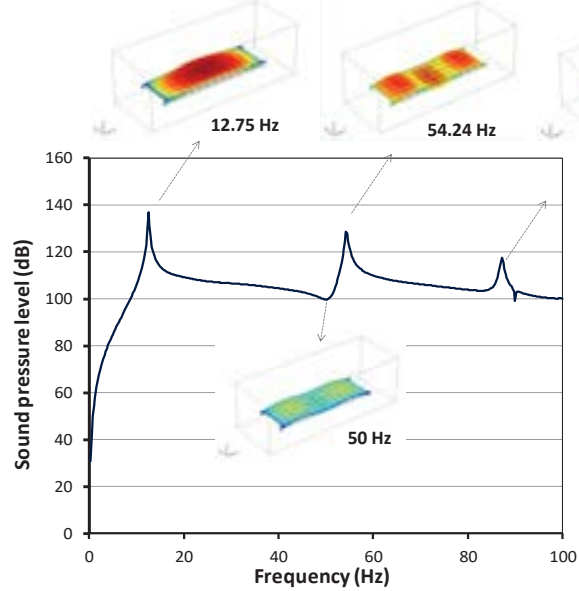

(a)

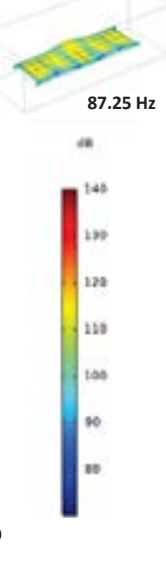
PAN_Fl_struts.

\section{CONCLUSIONS}

In the present work attention is focused on the dynamic and vibroacoustic response of timber floor panels as well as the study of the effect of the damping ration. In this study the two panels of PAN_Fl and PAN_Fl_stucts were analysed in static and dynamic analyses. Based on the findings of this study new conclusions are drawn :

i. The validation of the numerical simulation is based on the envelope experimental behavior of the two difference floor panel. The response of the panel PAN_Fl was used to build the numerical model while the response of the panel PAN_Fl_struts was used to validate the previous model.

ii. The success of the deployed numerical simulation is fully demonstrated by comparing the shape of the load-displacement curves with the experimental ones. Therefore, it is a reliable tool for the simulation of the hysteretic behavior of these timber floor panels and can be used in further studies.

iii. The peak values of a transient vibration are governed by system stiffness and mass, but not by damping. Damping is a measure of how quickly the response of vibrating system decay after the loading period; as a result the effects of the damping during the walking 
loading of $2.6 \mathrm{sec}$ were not as much remarkable. The comparison of the results shows that the maximum vertical displacement was reduced $1.4 \%$ for the PAN_Fl and $0.5 \%$ for the PAN_Fl_struts according to damping, while the maximum acceleration in the middle of the span was reduced equal to $10 \%$ and $2.5 \%$ respectively.

iv. The analysis of the vibroacoustic response of the system made it possible to identify the most radiant resonance frequencies.

\section{REFERENCES}

[1] S. Fuentes, E. Fournely \& A. Bouchaïr, Experimental study of the in-plan stiffness of timber floor diaphragms. European Journal of Environmental and Civil Engineering, 18:10, 1106-1117, 2014.

[2] CEN. 2004. EN 1995-1-1:2004, Eurocode 5: design of timber structures. Part 1-1: general common rules and rules for buildings. European Committee for Standardization, Brussel, Belgium.

[3] H. Bachmann, and W. Ammann, Vibrations in structures induced by man and mechanics. IABSE - AIPC - IVBH, Switzerland,1987.

[4] M.S. Williams, and P. Waldron, Evaluation of methods for predicting occupantinduced vibrations in concrete floors. The Structural Engineer, 72(20), 334-340, 1994.

[5] J.G.S. Da Silva, P.C.G. Da S. Vellasco, de Andrade, F.J.C.P. da Soeiro, and R.N Werneck, An evaluation of the dynamical performance of composite slab. Computers and Structures, 81, (18-19), 1905-1913, 2003.

[6] A. Ebrahimpour, and R.L. Sack, A review of vibration serviceability criteria for floor structures. Computers and Structures, 83, 2488-2494, 2005.

[7] W. Larbi, Numerical modeling of sound and vibration reduction using viscoelastic materials and shunted piezoelectric patches. Computers \& Structures, 232, 105822, 2020.

[8] M. Titirla, P. Papadopoulos, I. Doudoumis, Finite Element modelling of an innovative passive energy dissipation device for seismic hazard mitigation. Engineering Structures, 168, 218-228, 2018.

[9] W. Larbi, L. Pereira da Silva, J.-F. Deü, An efficient FE approach for attenuation of acoustic radiation of thin structures by using passive shunted piezoelectric systems. $\mathrm{Ap}$ plied Acoustics, 128, 3-13, 2017.

[10] M. Titirla, K. Katakalos, Evaluation of an innovative passive mitigation device through experimental and numerical investigation. COMPDYN 2017, 6th ECCOMAS Thematic Conference on Computational Methods in Structural Dynamics and Earthquake Engineering, Rhodes Island, Greece; 06/2017.

[11] W. Larbi, J.-F. Deü, R. Ohayon, Finite element formulation of smart piezoelectric composite plates coupled with acoustic fluid. Composite Structures, 94 (2), 501-509, 2012.

[12] M.D, Titirla, P.Papadopoulos, Finite Element investigation of a new seismic energy absorption device. COMPDYN 2015, 5th ECCOMAS Thematic Conference on Computational Methods in Structural Dynamics and Earthquake Engineering, Crete Island, Greece; 05/2015.

[13] R.R. Craig, A.J. Kurdila, Fundamentals of Structural Dynamics, 2nd Edition, Wiley, ISBN 978-0-471-43044-5, 2006.

[14] A.K. Chopra, Dynamics of structures - Theory and Applications to Earthquake Engineering, Prentice Hall - Pearson Highered, 2012. 
[15] ISO 10137 Bases for design of structures - Serviceability of buildings and walkways against vibrations, Second edition, International Organization for Standardization, 2007.

[16] L.J. Hu, Y.H. Chui, D.M. Onysko, Vibration serviceability of timber floors in residential construction. Prog. Struct. Eng. Mater. 3, 228-237, 2001.

[17] J. Weckendorf, B. Zhang, A. Kermani, D. Reid, Damping characteristics of timber flooring systems. The 10th world conference on timber engineering (WCTE10), Miyazaki, Japan; June 2008.

[18] B. Zhang, J. Weckendorf, A. Kermani, Vibrational performance of metal-webbed timber floors. The 11th world conference on timber engineering (WCTE-11), Riva del Garda, Trentino, Italy; June 2010.

[19] British Standards Institution. UK NA to BS EN 1995-1-1:2004+A1:2008 UK National Annex to Eurocode 5: Design of timber structures - Part 1-1: General - Common rules and rules for buildings; 2009.

[20] M. Titirla, E. Ferrier, L. Michel, On the mechanical behaviour of innovative moment connections between composite floor panels and glulam columns, International Journal of Architectural Heritage - Conservation, Analysis, and Restoration, 2020 doi.org/10.1080/15583058.2020.1836529.

[21] M. Titirla, L. Michel, E. Ferrier, Mechanical behaviour of glued-in rods (carbon and glass fibre-reinforced polymers) for timber structures - An analytical and experimental study, Composite Structures, 208,70-77, 2019.

[22] M. Titirla, L. Michel, E. Ferrier, Mechanical behavior of hybridal floor panels to timber columns joints, 9th International Conference on Fibre-Reinforced Polymer (FRP) Composites in Civil Engineering (CICE 2018), Paris, France, 17-19 July 2018.

[23] M. Titirla, L. Michel, E. Ferrier, Innovative connections between hybrid floor panels and timber columns able to reduce the deflection of the panels big span. COMPDYN 2019, 7th ECCOMAS Thematic Conference on Computational Methods in Structural Dynamics and Earthquake Engineering, Crete Island, Greece; 24-26 June 2019.

[24] FC Harper, WJ Warlow, BL Clarke, The forces applied to the floor by the foot in walking. Wear 4(6):495-497, 1961.

[25] W. Larbi, J.-F. Deü, R. Ohayon, Vibroacoustic analysis of double-wall sandwich panels with viscoelastic core, Computers \& Structures, 174, 92-103, 2016.

[26] W. Larbi, J.-F. Deü, M. Ciminello, R. Ohayon, Structural-acoustic vibration reduction using switched shunt piezoelectric patches: A finite element analysis, Journal of Vibration and Acoustics, 132 (5), 051006, 2010

[27] N. Reboul, C Grazide, N. Roy, E. Ferrier, Acoustic emission monitoring of reinforced concrete wall-slab connections, Construction and Building Materials, 259, 2020. 